\title{
Service design and circular economy in the fashion industry
}

\author{
Approaches to increase user acceptance of circular clothing models
}

\author{
Ingrid Kongelf ${ }^{1}$, Juana Camacho-Otero ${ }^{1}$ \\ ${ }^{1}$ Department of Design, Norwegian University of Science and Technology \\ ingrid.kongelf@hotmail.com \\ juana.camacho-otero@ntnu.no
}

\begin{abstract}
This article investigates through a literature review how considering factors in fast fashion and service design aspects can help address user acceptance challenges in circular clothing models, with the aim of designing more attractive models for consumers. Fast fashion has significantly increased in popularity over the last decades and is creating escalating environmental, economic and social challenges related to overproduction and overconsumption. The circular economy is seen as a way to address these sustainability challenges but is facing issues with low user acceptance among consumers. The results of this review suggest that consumer advantages and disadvantages of fast fashion can help inform better circular clothing models, but that circular clothing models might also provide other benefits for consumers. Moreover, the article discusses how service design can be valuable in addressing user acceptance challenges within different circular clothing models, as they can both be viewed as approaches to shift from offering products to offering value and benefits. Further on, service design is of value when needing to understand consumers, as it is human-centred and collaborative by nature. In conclusion, the article suggests that service design and fast fashion can in different ways contribute to the understanding of how to design more attractive circular clothing models, in order to increase user acceptance among consumers.
\end{abstract}

Keywords: user acceptance, circular economy, service design, fast fashion, literature review

\section{Introduction}

The concept of fast fashion ${ }_{2}$ quick turnaround of new styles, increased number of collections offered each year, and lower prices (Ellen MacArthur Foundation, 2017; Joy, Sherry, Venkatesh, Wang, \& Chan, 2012) has significantly increased in popularity over the last decades and is identified by a very linear way of production and consumption: take, make, use and dispose. As a result of this, the industry poses substantial environmental, economic and social challenges (Brooks, Fletcher, Francis, Rigby, \& Roberts, 2017). In fact, the fashion industry is responsible for around $10 \%$ of global greenhouse gas emissions, more than aviation and 
shipping combined (UN Climate Change, 2018). Moreover, we now buy on average $60 \%$ more clothing than just 15 years ago, and each item is kept for only half as long (UN Environment, 2019). The fashion industry is big business, valued at around $\$ 2.4$ trillion. However, due to the lack of recycling and overproduction of garments, it loses about $\$ 500$ billion in value every year (UN Environment, 2019). Moreover, the business is characterised by social challenges, such as underpayment, forced and child labour (Reichart \& Drew, 2019). Hence, there are clear environmental, economic and social incentives present today for the industry, consumers and system to enforce change. To meet the UN Sustainability Goals by 2030, especially Goal 12 Responsible Consumption and Production, we need to move away from the concept of fast fashion; better exploiting the utilisation potential of clothes and substituting the purchase of new garments (Fletcher, 2015; Klepp \& Laitala, 2016). A part of this is to ensure a broad and attractive offer of sustainable and circular fashion business models.

The circular economy (CE) revolves around moving away from the current linear economy towards a circular approach and can be applied in shaping more sustainable clothing consumption. The circular economy has noble environmental aims but faces acceptance and diffusion challenges. It is aimed at generating profits from the offer and flow of services, materials and products (Bocken, de Pauw, Bakker, \& van der Grinten, 2016; Cherry \& Pidgeon, 2018 ) and the goal is keeping products and materials in use, designing out waste and pollution and regenerating natural systems (Ellen MacArthur Foundation, 2019b). To achieve such change, focus and efforts are required at system, production and consumption levels in society (Mylan, 2015). As stated by Camacho-Otero et al. (2018), recent reviews of the circular economy have indicated that cultural barriers and lack of user acceptance are significant factors hindering the diffusion of such business models and that less attention has been paid to how consumers would affect and be affected by these models. This has also been shown specifically in alternative forms of clothing consumption (Camacho-Otero, Boks, \& Pettersen, 2019; Gwozdz, Nielsen, \& Müller, 2017; Tukker, 2015; Vezzoli, Ceschin, Diehl, \& Kohtala, 2012). Therefore, as circular economy models can cause substantial changes to people's lives (Camacho-Otero, Boks, \& Pettersen, 2018), it is essential for user acceptance and diffusion to involve these people when designing circular models.

The role of design can be described as enabling change and can serve as a tool and approaches for gathering information and developing and implementing interventions (Pettersen, 2015). It can, therefore, be relevant for sustainable development. Service design, in particular, is an approach aimed at understanding people and systems, accommodating changes in behaviour and on system level over time. The aim is to use services as a tool to decouple value creation from resource use, enhancing environmental, economic and social perspectives (Bocken et al., 2016; Polaine, Løvlie, \& Reason, 2013). Therefore, this article seeks to investigate how to exploit the mindset and approaches of design and service design to better apply circular business models to the fashion industry.

Through a literature review, this article seeks to investigate the relationship between fast fashion, circular economy business models, and service design, to consider aspects relevant for designing better circular clothing models. Specifically, it aims at answering the questions: what are the factors for user acceptance in fast fashion and how can this help inform the design of better circular clothing models? What are acceptance challenges in circular models, and in what ways can service design help address such aspects to design better models? The review examines existing research on the fields of factors of user acceptance in fast fashion, circular economy business models and their acceptance challenges and service design. 
Below is a description of the method used in the work with this article, followed by the results of the literature review. Firstly, the result section presents factors of user acceptance in fast fashion, then discusses a framework for different circular economy models and their acceptance challenges, and lastly, presents a section on service design. Thereafter, in the discussion, the article argues how these three fields can help address each other's challenges. The conclusion appears at the end of this review article.

\section{Method}

This article is based on a literature review of research papers on the three topics of user acceptance factors of fast fashion, circular economy business models in general and specifically for apparel consumption, and service design. The papers were mostly sourced through purposely sampling of relevant papers. The work has followed a qualitative approach, mainly relying on the back and forth snowball technique to identify core papers and to find additional papers in the references of relevant work. For sourcing papers on fast fashion, specific journals on the topic such as the Journal of Fashion Marketing and Management were targeted. Resources on service design were mostly sourced from relevant textbooks, as a more general approach to the field's understanding was of benefit to this paper.

\section{Results}

\subsection{Consumer advantages and disadvantages of fast fashion}

How we perceive clothes and address meaning to them have impacts on how we use and consume them, and this can influence the shift to more sustainable consumption practices. Gabrielli et. al. (2013) suggests that the consumption of fashion serves as a tool to express and shape personal lifestyle and identity. It stretches beyond simply needing something to wear and is therefore closely intertwined with deeper meaning creation linked to personal interests. This is important to consider when aiming to change clothing practises, as people might be more reluctant to change. Another obstruction to a more sustainable and circular fashion industry is the fact that much clothing is treated as disposable, discarded long before the end of life because of style or trend implications (Lang \& Joyner Armstrong, 2018). In the following sections, consumer advantages and disadvantages identified in the literature are presented.

\subsubsection{Consumer advantages}

Some perceived benefits from the consumer perspective of fast fashion have been identified in the literature, and these are presented in the following section and in summary in Table 1.

Table 1. Consumer advantages of fast fashion

\begin{tabular}{l|l}
\hline Consumer advantages of fast fashion & Authors \\
\hline Low prices & Gabrielli et al., (2013), Ozdamar Ertekin \& Atik, (2014) \\
\hline Freedom of choice & Gabrielli et al., (2013), Ozdamar Ertekin \& Atik, (2014) \\
\hline Following latest trends inexpensively & $\begin{array}{l}\text { Gabrielli et al., (2013), Kim et al., (2013), Ozdamar Ertekin \& } \\
\text { Atik, (2014) }\end{array}$ \\
\hline Provides a social arena & Gabrielli et al., (2013), Kim et al., (2013) \\
\hline
\end{tabular}

Firstly, low prices are an important positive factor of fast fashion, as it allows for freedom of purchase, being able to find a 'good deal' and requiring little economic and emotional investment (Gabrielli, Barnes, Baghi, \& Codeluppi, 2013; Ozdamar Ertekin \& Atik, 2014). 
Next, fast fashion also allows for great freedom of choice. It offers large amounts of garments on display (Gabrielli et al., 2013), extensive varieties of sizes and styles (Ozdamar Ertekin \& Atik, 2014), is very convenient and permits acquiring 'out of ordinary style or taste' garments (Gabrielli et al., 2013). Then, it also serves the need for being up to date or following the latest trends rather inexpensively, as the business is categorised by high speed, quick turnover of styles and trendy or up-to-date looks every week (Gabrielli et al., 2013; Kim, Barnes, Jung Choo, \& Yoon, 2013; Ozdamar Ertekin \& Atik, 2014). Finally, fast fashion shopping also provides a social arena and conversation topics for exchanging experiences and tips (Gabrielli et al., 2013), and a complete in-store experience coloured by hedonic lifestyles (Gabrielli et al., 2013; Kim et al., 2013).

\subsubsection{Consumer disadvantages}

Some perceived consumer disadvantages of fast fashion have also been identified in the literature, and these are presented in the following paragraphs and in summary in Table 2.

Table 2. Consumer disadvantages of fast fashion

\begin{tabular}{l|l}
\hline Consumer disadvantages of fast fashion & Authors \\
\hline Low quality of products & $\begin{array}{l}\text { Gabrielli et al., (2013), Kim et al., (2013), Ozdamar Ertekin \& } \\
\text { Atik, (2014) }\end{array}$ \\
\hline Low quality of service experience & Gabrielli et al., (2013), Kim et al., (2013) \\
\hline Encourages overconsumption & Gabrielli et al., (2013), Ozdamar Ertekin \& Atik, (2014) \\
\hline Irresponsible business model & $\begin{array}{l}\text { Ozdamar Ertekin \& Atik, (2014), Gabrielli et al., (2013), Kim } \\
\text { et al., (2013) }\end{array}$ \\
\hline Deindividuation and homogenization of design & Ozdamar Ertekin \& Atik, (2014), Kim et al., (2013) \\
\hline
\end{tabular}

Firstly, the perhaps largest disadvantage of fast fashion is its low quality of products (Gabrielli et al., 2013; Kim et al., 2013; Ozdamar Ertekin \& Atik, 2014). However, due to its low price point, consumers seem to expect this and subsequently lower their expectations regarding garment quality. The service experience is also of low quality, as stores can be large and complex with little assistance from employees (Gabrielli et al., 2013; Kim et al., 2013). Secondly, fast fashion encourages impulsive, rapid and mindless overconsumption (Gabrielli et al., 2013; Ozdamar Ertekin \& Atik, 2014), perhaps without satisfying real user needs. This is extensively managed through the irresponsible business model, including artificial newness and planned obsolescence (Ozdamar Ertekin \& Atik, 2014), overly trendy items and short-lived or poor aesthetics (Gabrielli et al., 2013; Kim et al., 2013; Ozdamar Ertekin \& Atik, 2014). Lastly, deindividuation and homogenization of design are common in fast fashion (Ozdamar Ertekin \& Atik, 2014), as international stores carry the same garments, and as rip-offs of high fashion creates inauthenticity down the line (Kim et al., 2013).

In short, despite fast fashion's apparently negative sides (both from the consumer and sustainability perspective) it has clear qualities that in different ways counterbalance those negative effects. In one way, the fast fashion product might represent a compromise between what people would like to buy often, and what they can actually afford (Gabrielli et al., 2013). However, as the fast fashion industry follows a model that is inherently unsustainable both for people and the planet, space is growing for more sustainable alternatives like slow fashion.

Slow fashion can be seen as the opposing force to fast fashion, as its goals are to slow down consumption and production processes, and at the same time assure the well-being of industry 
workers, communities and the environment (Ozdamar Ertekin \& Atik, 2014). Specifically, the word 'slow' lays promises of increased focus on slowing down the number of trends and seasons, encouraging better quality production to increase (both perceived and real) value of garments (Ozdamar Ertekin \& Atik, 2014). Naturally, this approach also leads to diverse and perhaps unconventional business models for the fashion industry, such as second hand and vintage stores, leasing and renting, clothes swapping and recycling (Ozdamar Ertekin \& Atik, 2014), and also redesign, upcycling and online peer to peer clothing marketplaces. Many of these models can be placed under the circular economy.

\subsection{Circular economy business models}

As described in the introduction, the circular economy aims to design out waste and pollution, moving to a circular and closed loop system for products and resources. A closed loop system means there are only two ways of dealing with unwanted or waste material: either reuse and recycling or dissipative loss for consumables (Bocken et al., 2016). Based on the work by Bocken et al. (2016), there are three approaches to closed loop recycling: slowing, closing and narrowing resource loops.

Slowing resource loops is concerned with extending and intensifying the use phase of products through the design of long-life goods and product-life extension, aimed at slowing down the flow of resources (Bocken et al., 2016). Closing resource loops is related to the reuse of materials after recycling, aimed at closing the flow of resources (Bocken et al., 2016). Finally, narrowing loops is concerned with reducing resource use in production, but as it does not address the cycling or speed of goods, it is not seen as a viable approach for circular models (Bocken et al., 2016), and will therefore not be further addressed in this article. As a result, the following sections present circular business model strategies for slowing and closing resource loops only. An overview of the findings can be found in Table 3, together with more specific examples of circular clothing models.

Table 3. Overview of CE model strategies and specific circular clothing models

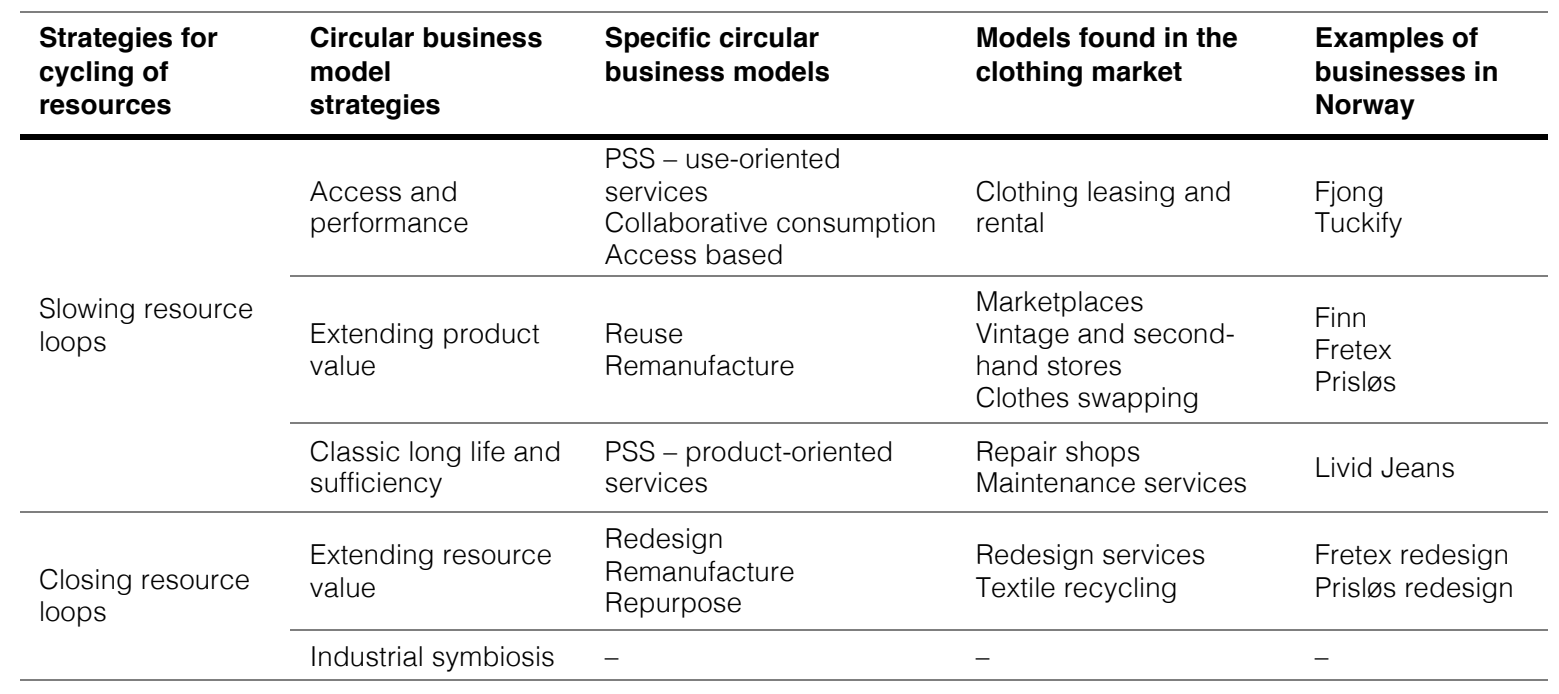

\subsubsection{Circular economy models for slowing loops}

Present in the strategy of slowing resource loops is the access and performance model, the extending product value model and the classic long life and sufficiency model. 
Access and performance models are described as satisfying user needs without any shift of ownership (Bocken et al., 2016); the users will never own the products they use but attain access to them by paying a fee. Other concepts describing similar models include product-service systems (PSS) (particularly use-oriented services) (Tukker, 2015), access based models and collaborative consumption (leasing in particular) (Lang \& Joyner Armstrong, 2018). More closely linked to apparel consumption models we find clothing rentals and clothing leasing (subscription based) as subcategories to access and performance models. In Norway, two examples of such business are Fjong and Tuckify. Fjong is a rental service for women's vintage and new designer clothing, focusing on high quality items. Tuckify is a rental and subscriptionbased service for baby and children's clothing.

Access and performance models can bring great sustainability benefits, as they increase the usage of often underutilized products (Lang \& Joyner Armstrong, 2018) and can more easily fulfil consumer needs with fewer products. The model can also motivate and incentivises companies to make products of high quality extending their service lives, as products now become cost factors in the service offer (Tukker, 2015). Accordingly, such models can help delink value creation from material use (Vezzoli et al., 2012) as the focus moves from selling products to fulfilling needs.

Seen from the consumer perspective, there are perceived benefits of using access and performance models and its aforementioned subcategories. Firstly, it can reduce the cost of acquiring products and people can share the cost between them, and also make luxury items available which would otherwise be out of bounds (Lang \& Joyner Armstrong, 2018). Secondly, the model can reduce the 'burden' of ownership (Lang \& Joyner Armstrong, 2018), especially in terms of maintenance, repair and storage. Lastly, more closely linked to apparel, it can give access to a large selection of garments and to the latest fashion items (Lang \& Joyner Armstrong, 2018; Tukker, 2015).

The access and performance model can be viewed as the most radical of the circular economy models presented here, thus also struggling with low user acceptance among consumers (Vezzoli et al., 2012). There are multiple reasons for this, but the most fundamental one might be the need for radical changes in practises, behaviours and thinking (Vezzoli et al., 2012). Another factor is how this model negatively affects modes of materialism (Lang \& Joyner Armstrong, 2018), including little control or ownership over artefacts (Mylan, 2015; Tukker, 2015) and the strong symbolic value of owning products, particularly highly visible, expressive and personal products (Mylan, 2015) such as clothing. Further on, comparing the access and performance model to more conventional clothing business models, factors such as lack of easy access, lower intangible value (brand value, the 'priceless' experience etc.), hygiene risk of used clothes, lack of trust in service provider (Lang \& Joyner Armstrong, 2018), and limited behavioural freedom becomes more evident (Tukker, 2015).

Extending product value is a model based around the reuse and remanufacturing of products, turning them into 'as new' affordable products for consumers (Bocken et al., 2016). In the apparel market, this model can take the form as marketplaces for preowned items (often peer to peer online), vintage and second-hand stores and clothing swap events (a form of collaborative consumption). This model is closer to regular clothing business models, as there is a transfer of ownership and in some cases, a physical store is involved. Here, some Norwegian business examples of this model include Finn, Fretex and Prisløs. Finn is an online peer to peer marketplace for buying and selling used (or new) products, including clothes. Fretex is Norway's largest second-hand store chain offering clothes, furniture and sports equipment, 
while Prisløs is a reuse collective in Trondheim selling second-hand and vintage garments sourced locally and internationally.

Sustainability benefits of this model are the extended use of products without the need for much alterations or new resource input, simultaneously decreasing the need for new products entering the market. Perceived consumer benefits of this model (in particular clothing swapping) are the social arenas they produce, meeting new and perhaps likeminded people and being involved in an activity (Lang \& Joyner Armstrong, 2018). These models also serve as an opportunity to attain unique and different garments, perhaps distinguishing oneself from others.

Because extending product value models are perceived as less radical compared to conventional clothing models, they also enjoy a wider diffusion and acceptance among consumers. Although this category included a wide variety of business models, one can still make some general statements about what might hinder user acceptance of such models. Some factors identified in this article are the fact that used clothes are perceived as 'unclean' from a cultural perspective (Klepp \& Laitala, 2016) and that the models might offer a smaller range of choices regarding size and fit.

The classic long life model is concerned with producing products of high quality, aimed at a long use life (Bocken et al., 2016). The value proposition often includes a high service level in the form of repairs, warranties and maintenance, often inducing a 'premium' price for the products (Bocken et al., 2016). PSS, especially product oriented service (Tukker, 2015), can be contained in this category. Encouraging sufficiency means having a non-consumerist approach to sales in addition to focusing on the aspects of classic long life products (Bocken et al., 2016). As such, the sustainability benefits of such a model can be the increased quality of garments and service offerings, and consequently the perceived extended life and value of products. A Norwegian business example of the classic long life model is Livid Jeans. Livid is a clothing label focusing on producing ethical and high-quality garments, and also offer vintage garments and repair services in their stores. First time repairs are included when purchasing jeans.

The classic long life and sufficiency model can in many cases be viewed as simply a variety to conventional clothing models. However, factors hindering user acceptance are still present, with the common premium price being one of them. Competing products might often be of lower quality but can also have a significantly lower price point. Also, the need for change in behaviour regarding repair and maintenance services can hinder user acceptance, especially if access to these is limited, inconvenient or time-consuming.

\subsubsection{Circular economy models for closing loops}

Present in the strategy of closing resource loops is the models of extending resource value and industrial symbiosis. As these models are seen as less beneficial in terms of sustainability aspects and of less relevance to the clothing industry, they are treated more shortly for overview purposes. Extending resource value involves using what can be considered waste or products at the end of their useful lives to make new products (Bocken et al., 2016). This can for the apparel market, for example, include redesign or repurpose of old fabrics into new garments, or textile recycling. Two examples of this model in Norway are Fretex redesign and Prisløs redesign. Fretex redesign is a department of Fretex focusing on the repurpose of old garments and fabrics into new clothes for sale. Prisløs redesign has a similar scope in repurposing secondhand fabric, like curtains and bed sheets or old clothes, into new garments for sale. Industrial symbiosis is similar to extending resource value in terms of turning waste from one production 
process into resources for another one (Bocken et al., 2016). However, this model is mostly located at the manufacturing level, concerned with exploiting production scrap.

As different circular economy models are facing challenges with user acceptance, the next section presents the nature of service design to understand what aspects might be beneficial to apply in the design of circular clothing models.

\subsection{Service design}

Service design is a highly practical approach aimed at the creation and improvement of offerings made by organizations through a human-centred and holistic process (Stickdorn, Lawrence, Hormess, \& Schneider, 2018). It concerns shaping the value creation, experience, touchpoints and flow of a service to meet its user's needs. Further on, service design has six core principles, as stated by Stickdorn et al. (2018). It is [1] human-centred; considering the experiences of all people affected by the service, [2] collaborative; stakeholders are engaged in the design process of the service, [3] iterative; exploring, learning and testing along the process, [4] sequential; the service is visualized and managed as sequences of interrelated actions, [5] real; the design of the service should be performed in the real world and in proper context, and finally [6] holistic; considering all stakeholders needs across the full service and system network. Moreover, services are of nature complex, including both people and artefacts, and therefore has a focus on how these interact with one another throughout the delivery of the service (Segelström, 2013).

\subsubsection{How does service design approach people and services?}

Service design can be described as being human-centred. Specifically, if a service is seen as a means to deliver value to its customer, a service-centred view needs to put the customer at the centre of its activities (Segelström, 2013). Therefore, when designing services, the service designer needs to consider all the stakeholders: the people and nonhuman actors (such as organizations or laws) influencing or being influenced by the service (Segelström, 2013). Understandings around context, use patterns and needs of stakeholders can be achieved through interviews, observations and other qualitative methods (Segelström, 2013), getting insights into the service from different stakeholder's points of view (Kimbell, 2011). However, degrees of uncertainty about user requirements and actual use patterns in real life will always be present, which is why design processes are by nature iterative and strongly value user evaluations (Pettersen, 2015), user involvement and feedback. This is viewed as a way of reducing the risk of failure to meet stakeholder's needs when a final service or system is implemented (Pettersen, 2015).

\subsubsection{How can service design address sustainability?}

As mentioned in the introduction, the circular economy is based around moving from offering products, to generating value from the offer and flow of services, materials and products. As stated by Polaine et al. (2013), service design has a role to play in the transition of economies from valuing products to valuing benefits, as services focus on the value and benefits delivered, and not solely on the offering of products. In this way, the circular economy and service design have similar focuses. Moreover, such a transition consequently requires behavioural change in both consumers, organisations and society (Polaine et al., 2013), and service design as a, specifically, human-centred, collaborative and holistic approach can be an enabler of behavioural and system-level change. Implementing the shift from offering products to valuing benefits can be a major challenge, as stakeholders need to accept something (perhaps radically) new and less familiar (Polaine et al., 2013). Fortunately, design has certain attributes enabling it to cope with such 'wicked problems', as it can be seen as "key to innovations because it 
involves generating new concepts and new knowledge" (Kimbell, 2011). Thus, it can be used to map current and envisioning future situations of 'use' (Pettersen, 2015) and for achieving group level change or exploring novel ways of doing (Pettersen, 2015). In summary, service design holds key qualities containing a strong focus on users, has a holistic and iterative approach and can help generate new ideas: increasing the ability to adapt and change. These qualities give it a role to play in adapting the economy to a more resource-efficient one, as system-scale behaviour change is needed from both organizations and consumers over time.

\section{Discussion}

This article has so far presented a review on research of the topics of user acceptance factors for fast fashion, circular economy models and the field of service design. Next, the article will discuss how these fields can help address each other challenges, and how this insight can perhaps help design better circular clothing models.

The circular economy aims to move away from today's linear economic system, which in the case of the clothing industry means to move away from the fast fashion concept. To be able to make a transition from the current situation to a preferred one, understanding the existing system is crucial for the transition's success. Therefore, understanding fast fashion; what makes it successful and what hinders its acceptance, can be valuable to design attractive circular clothing models. If circular clothing models (in combination or individually) are able to match both fast fashions advantages (low prices, freedom of choice, high convenience, being up to date and serve as a social arena) and simultaneously address it's disadvantages by offering high quality in garments and experience, being responsible towards consumption and offering aesthetically long-lived and unique garments, they will be better equipped for acceptance and diffusion among consumers. Yet, circular models might also offer other types of benefits not present in fast fashion, such as environmental arguments, and unique and higher quality garments at reduced prices. Therefore, fast fashion should be viewed as a place for inspiration, not necessarily holding all preconditions for attractive circular clothing models.

Furthermore, the literature points out challenges with consumer acceptance in many circular economy models, in part due to limited user understanding and involvement. Fortunately, service design offers tools to cope with such issues and can be exploited when developing and implementing circular solutions, as they are both aimed at creating value and benefits, with less focus on the actual product delivered. In terms of user acceptance challenges for circular models identified in the literature, service design can take part in addressing these in different ways. Carefully crafting the service experience of accessed clothes, perhaps with elements of customization, can help with the issues of ownership and materialism, as this can strengthen the bond between the user, the product, and the service. Next, focusing on the experience of the service delivery through user involvement, iterative testing and feedback in real context can also aid in the issues with easy access, as user pain points can be discovered early and handled iteratively. In terms of issues with the 'cleanliness' of used garments, the desire for newness or novelty and perceived benefits of offers, the presentation and framing of garments, the store or space of interaction and the experience can be crucial in terms of how they will be perceived. To do this properly, a thorough understanding of the users, their needs and attitudes are of the essence and can be attained through the human-centred and collaborative nature of service design. Still, one should take into strong consideration the very personal manner clothes serve to many people, as this can pose challenges to change in attitudes and behaviour towards clothing consumption and use. 
Further on, the convenience of sustainable clothing models is of the essence, as it is not enough to be the 'greener' choice, it also has to be accessible, practical and attractive, on the same level as the consumer's other alternatives. And what will be considered alternatives might differ, as people value different aspects. Therefore, understanding people and their context are crucial in order to meet them at the right 'place and moment'. Service design with its human-centred, real and holistic process is a good approach to better understanding these factors. If you want people to change their way of doing something, make it the best alternative: "As Kurt Lewin the pioneer of organisational psychology observed, the best way to create positive change is not to incentivise, but to create systems where people can behave better effortlessly." (Ellen MacArthur Foundation, 2019a). Figure 1 summarises the discussion and the results of the work presented.

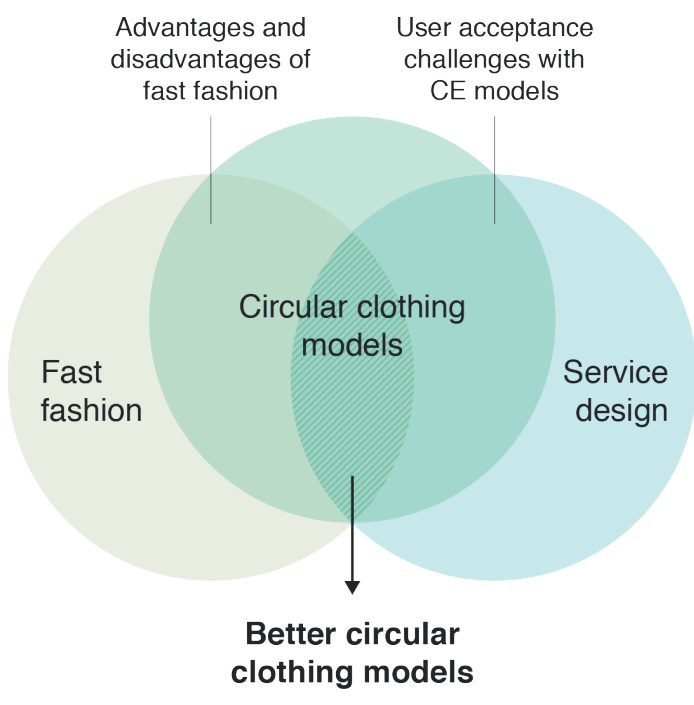

Figure 1. Overview of main results from the review

Finally, service design can also be seen as a good approach when novel ways of thinking and doing are required, as is the case in the bigger picture of the arising climate crisis and resource scarcity, and more specifically in the circular economy. Service design holds several qualities relevant to developing radically new ideas. Firstly, it's iterative approach can explore novel ways of doing, it's holistic approach can involve new people and aspects to spark novel ideas, and lastly, it's real approach can perhaps explore new contexts. In general, design can be seen as a way to generate new concepts and knowledge, serving the needs of some of the circular economy challenges.

\section{Conclusion}

The review has shown that understanding fast fashion's advantages and disadvantages can help inform the design of better circular clothing models, to increase the acceptance and diffusion of such models among consumers. Further on, service design has been argued to be a good approach for tackling user acceptance challenges within circular clothing models, for understanding and designing for users of such models and as an approach to develop new concepts and insights. In conclusion, service design can in different ways contribute to the understanding of how to design better and more attractive circular clothing models.

There are some limitations to this study. Firstly, it is not an exhaustive study, and articles have been purposely included and others deliberately excluded from the work. Fewer core papers 
were identified in this review as relevant for the advantages and disadvantages of fast fashion compared to the circular economy and service design, as there was a smaller body of work on this topic. Hence, there is an opportunity for more research in this field. Lastly, some of the articles on fast fashion and circular models described examples or studies in specific countries, so in this review, some specific results have been generalised as it was found viable to do so. The hope is that this article can be used as inspiration and as a source of information into projects aimed at shifting clothing consumption habits. It can be used for better understanding today's fast fashion context, getting insights into circular models relevant for clothing consumption, highlighting the important aspects when designing circular clothing models and understanding how valuable service design can be in tackling these issues.

\section{Citations and References}

Bocken, N. M. P., de Pauw, I., Bakker, C., \& van der Grinten, B. (2016). Product design and business model strategies for a circular economy. Journal of Industrial and Production Engineering, 33(5), 308-320. doi:10.1080/21681015.2016.1172124

Brooks, A., Fletcher, K., Francis, R. A., Rigby, E. D., \& Roberts, T. (2017). Fashion, Sustainability, and the Anthropocene. Utopian Studies, 28(3), 482-504. doi:https://doi.org/muse.jhu.edu/article/686649

Camacho-Otero, J., Boks, C., \& Pettersen, I. (2018). Consumption in the Circular Economy: A Literature Review. Sustainability, 10(8). doi:10.3390/su10082758

Camacho-Otero, J., Boks, C., \& Pettersen, I. N. (2019). User acceptance and adoption of circular offerings in the fashion sector: Insights from user-generated online reviews. Journal of Cleaner Production, 231, 928-939. doi:10.1016/j.jclepro.2019.05.162

Cherry, C., \& Pidgeon, N. (2018). Why Is Ownership an Issue? Exploring Factors That Determine Public Acceptance of Product-Service Systems. Sustainability, 10(7). doi:10.3390/su10072289

Ellen MacArthur Foundation. (2017). A new textiles economy: Redesigning fashion's future. Retrieved from http://www.ellenmacarthurfoundation.org/publications

Ellen MacArthur Foundation. (2019a). Teemill: An open access circular supply chain for fashion Retrieved from https://www.ellenmacarthurfoundation.org/case-studies/anopen-access-circular-supply-chain-for-fashion

Ellen MacArthur Foundation. (2019b). What is the circular economy? Retrieved from https://www.ellenmacarthurfoundation.org/circular-economy/what-is-the-circulareconomy

Fletcher, K. (2015). Durability, Fashion, Sustainability: The Processes and Practices of Use. Fashion Practice, 4(2), 221-238. doi:10.2752/175693812x13403765252389

Gabrielli, V., Barnes, L., Baghi, I., \& Codeluppi, V. (2013). Consumption practices of fast fashion products: a consumer-based approach. Journal of Fashion Marketing and Management: An International Journal, 17(2), 206-224. doi:10.1108/jfmm-10-20110076

Gwozdz, W., Nielsen, K. S., \& Müller, T. (2017). An Environmental Perspective on Clothing Consumption: Consumer Segments and Their Behavioral Patterns. Sustainability, 9(5). doi:10.3390/su9050762

Joy, A., Sherry, J. F., Venkatesh, A., Wang, J., \& Chan, R. (2012). Fast Fashion, Sustainability, and the Ethical Appeal of Luxury Brands. Fashion Theory: The Journal of Dress, Body \& Culture, 16(3), 273-296. doi:https://doi.org/10.2752/175174112X13340749707123 
Kim, H., Barnes, L., Jung Choo, H., \& Yoon, N. (2013). The motivational drivers of fast fashion avoidance. Journal of Fashion Marketing and Management: An International Journal, 17(2), 243-260. doi:10.1108/jfmm-10-2011-0070

Kimbell, L. (2011). Designing for service as one way of designing services. International journal of design, 5(2), 41-52.

Klepp, I. G., \& Laitala, K. (2016). Klesforbruk $i$ Norge (2). Retrieved from http://www.hioa.no/extension/hioa/design/hioa/images/sifo/files/file80519 fagrapport nr. 2-2016 rapport klesforbruk.pdf

Lang, C., \& Joyner Armstrong, C. M. (2018). Collaborative consumption: The influence of fashion leadership, need for uniqueness, and materialism on female consumers' adoption of clothing renting and swapping. Sustainable Production and Consumption, 13, 37-47. doi:10.1016/j.spc.2017.11.005

Mylan, J. (2015). Understanding the diffusion of Sustainable Product-Service Systems: Insights from the sociology of consumption and practice theory. Journal of Cleaner Production, 97, 13-20. doi:10.1016/j.jclepro.2014.01.065

Ozdamar Ertekin, Z., \& Atik, D. (2014). Sustainable Markets: Motivating factors, barriers, and remedies for mobilization of slow fashion. Journal of Macromarketing, 35(1), 53-69. doi:10.1177/0276146714535932

Pettersen, I. N. (2015). Towards practice-oriented design for sustainability: the compatibility with selected design fields. International Journal of Sustainable Engineering, 8(3), 206218. doi:10.1080/19397038.2014.1001468

Polaine, A., Løvlie, L., \& Reason, B. (2013). Service Design: From insight to implementation Brooklyn, New York: Rosenfeld Media.

Reichart, E., \& Drew, C. (2019, 10.01.2019). By the numbers: the economic, social and environmental impacts of 'fast fashion'. Retrieved from https://www.wri.org/blog/2019/01/numbers-economic-social-and-environmentalimpacts-fast-fashion

Segelström, F. (2013). Stakeholder engagement for service design. (Doctoral dissertation), Linköping University, Linköping.

Stickdorn, M., Lawrence, A., Hormess, M., \& Schneider, J. (2018). This is service design doing (4th ed.). Sebastopol: O'Reilly Media.

Tukker, A. (2015). Product services for a resource-efficient and circular economy - a review. Journal of Cleaner Production, 97, 76-91. doi:10.1016/j.jclepro.2013.11.049

UN Climate Change. (2018). UN helps fashion industry shift to low carbon. Retrieved from https://unfecc.int/news/un-helps-fashion-industry-shift-to-low-carbon

UN Environment. (2019). UN Alliance For Sustainable Fashion addresses damage of 'fast fashion'. Retrieved from https://www.unenvironment.org/news-and-stories/pressrelease/un-alliance-sustainable-fashion-addresses-damage-fast-fashion

Vezzoli, C., Ceschin, F., Diehl, J. C., \& Kohtala, C. (2012). Why have 'Sustainable ProductService Systems' not been widely implemented? Journal of Cleaner Production, 35, 288-290. doi:10.1016/j.jclepro.2012.05.050 